\title{
Absence of amplification of the FGFR1-gene in human malignant mesothelioma of the pleura: a pilot study
}

Till Plönes ${ }^{* *}$, Frank Beckers ${ }^{1}$, Walburga Engel-Riedel ${ }^{1}$, Erich Stoelben ${ }^{1}$, Michael Brockmann ${ }^{2}$, Verena Schildgen ${ }^{2}$ and Oliver Schildgen ${ }^{2}$

\begin{abstract}
Background: Mesothelioma (MPM) is a rare malignant disease with a worse outcome. Fibroblast growth factor 1 (FGFR1) may be an interesting target for selective tyrosine kinases inhibitors (TKI) in MPM. The aim of this study was to evaluate the amplification of the FGFR1 gene in patients suffering from MPM.

Findings: We identified nineteen male patients treated in our department between August 2008 and July 2010 matching the inclusion criteria. Mean age was 68 years. Histopathological examination confirmed thirteen patients with epitheloid subtype, five with biphasic and one patient with sarcomatoid. Fluorescence in situ hybridization analysis revealed no polysomy nor an amplification of the FGFR gene copy number in any case.
\end{abstract}

Conclusion: Regarding that also EGFR amplifications in MPM are absolute rarities, our findings may be a hint that TKI's will not satisfy the hope for a new era in the treatment of MPM.

Keywords: Personal medicine, Pleural, Asbestos, Pleuropneumonectomy, Decortication, Chemotherapy

The malignant pleural mesothelioma (MPM) is an asbestos related highly aggressive malignancy arising from the pleural surface [1]. Despite all advances in diagnostic procedures and therapeutic options, which were made over the last decades, prognosis of MPM is still poor [2]. Most therapeutic strategies like common systemic chemotherapy can improve the overall survival for only a few months. However, alterations in receptor tyrosine kinases (RTK's) like over expression, mutation or amplification of has been identified as targets for patienttailored therapy in a broad spectrum of malignancies. In particular, "driver mutations", like epidermal growth factor receptor (EGFR), anaplastic lymphoma kinase (ALK) and others, are major players involved in the process of carcinogenesis. Physiologically regulating proliferation, apoptosis and cell motility, gene amplification and subsequent over expression of these genes lead to relevant activation of pro-oncogenic pathways

\footnotetext{
*Correspondence: Till.Ploenes@uni-wh.de

'Department of Thoracic Surgery, University Medical Center Witten/Herdecke, Lung Clinic Merheim, Campus Cologne, Ostmerheimerstrasse 200, 51109 Köln, Germany

Full list of author information is available at the end of the article
}

and correlates with response to tyrosine kinases inhibitors (TKI's). It has recently been suggested that the fibroblast growth factor 1 (FGFR1) may be an interesting target for selective TKI's in MPM [3]. Amplification of FGFR1 is already identified as a therapeutic target in lung cancer, but up to now the role of FGFR1 in mesothelioma is unclear [4].

The aim of this study was to evaluate the amplification of the FGFR1 gene in patients suffering from MPM.

In this retrospective study we investigated nineteen patients suffering from histologically proofed MPM. Histology was confirmed by thoracoscopy and classified according to the World Health Organization (WHO) criteria. All patients were treated in our department between 2008 and 2010. Patients were selected based on the following criteria: no chemotherapy prior tissue sampling, no other malignancy in the medical history and sufficient tissue sampling from the primary tumour. Clinical information was obtained by medical records and our medical data base. The study was approved by the local ethics committee (ethics committee of University of Witten/Herdecke, Nr. 126/2013). 
Table 1 Patients characteristics

\begin{tabular}{ll}
\hline & Value $\mathbf{n = 1 9}$ \\
\hline Age (years) (mean, standard derivation) & $68 \pm 9$ \\
Gender & Male $\mathrm{n}=19$ \\
Asbestos exposure* & $\mathrm{n}=11$ \\
Affected lung & left $\mathrm{n}=5$ \\
& right $\mathrm{n}=13$ \\
Histotype & epitheloid $\mathrm{n}=20$ \\
& biphasic $\mathrm{n}=4$ \\
& sarcomatoid $\mathrm{n}=1$ \\
\hline
\end{tabular}

"Anamnestic.

Gene copy number analysis of FGFR1 gene was investigated by FISH assay (Cytovision, Berlin, Germany) according to the manufactures instructions. FISH signals were analysed by microscopy performed by experienced molecular biologists blinded to the clinical parameters of each patient. FISH signals were classified in analogy to the HER-2/neu scoring recommendations and counted as amplification if a ratio of $>2.2$ was observed, whereas a ration $<1.8$ was counted a negative or not amplified. Due to the descriptive character of this study no further statistic methodology was used.

We identified nineteen male patients treated in our department between August 2008 and July 2010 matching the inclusion criteria. Mean age was 68 years. Histopathological examination confirmed thirteen patients with epitheloid subtype, five with biphasic and one patient with sarcomatoid. Ten patients disclosed exposure to asbestos, which was not confirmed histologically in any case (Table 1). Fluorescence in situ hybridization analysis revealed no polysomy nor an amplification of the FGFR gene copy number in any case (Figure 1).

\section{Findings}

The MPM is a highly aggressive malignancy, withstanding all current oncological treatment. The inhibition of RTK's may be a new treatment option in many malignancies and may be an opportunity in the frustrating treatment of MPM. The epidermal growth factor receptor (EGFR) for example is over expressed in many epithelial malignancies, against which TKI's has been developed. Although EGFR mutations are very rare, the expression status of EGFR in MPM has been noted in several publications [5]. The role of EGFR in MPM is until now unclear, but the fact that MPM is a mesenchymal and not an epithelial tumor may be a reason why the role of EGFR in MPM will remain limited. Therefore other RTK's has to be evaluated for treatment of MPM. Recently, FGFR1 has been identified as a potential therapeutic target for MPM in an experimental setting [3]. We examined in a pilot study nineteen tissue samples of patients suffering from MPM for amplification of FGFR1-gene. We could not discover any polysomy for FGFR gene in the investigated tissue samples, neither high nor low polysomy. Regarding that also EGFR amplifications in MPM are absolute rarities, this may be a hint that TKI's will not satisfy the hope for a new era in the treatment of MPM [6,7]. Further investigations concerning the role of RTK's and TKI's in MPM are urgently needed.

\section{Ethic's statement}

The study was approved by the local ethics committee (ethics committee of University of Witten/Herdecke, Nr. 126/2013).

\section{Consent section}

Written informed consent was not obtained from the patients according to the decisions of the ethics committee of University of Witten/Herdecke.

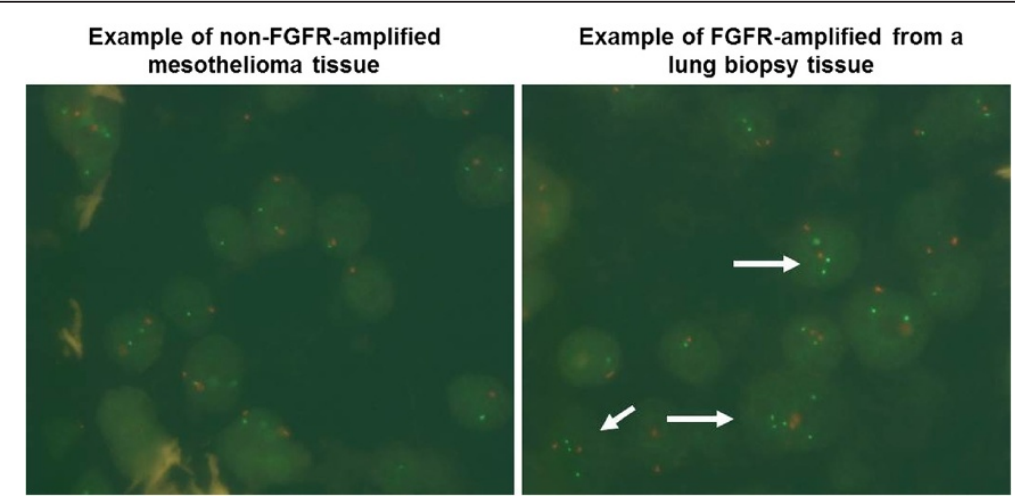

Figure 1 The figure shows a representative mesothelioma section $(5 \mu \mathrm{m})$ from FFPE tissue FISH stained with the FGFR probes from Zytovision, Germany (left panel). No amplification of FGFR (green signals) was observed. As control, a lung section with amplification of the FGFR gene is shown. The white arrows indicate cells in which the green signals are amplified in relation to the chromosal centromer controls (right panel). 


\section{Competing interests}

The authors declare that they have no competing interests.

\section{Authors' contribution}

TP identified the patients and collected the clinical parameters. TP wrote the manuscript and applied for the votum of the local ethics committee. OS and VS performed the FISH assay and interpretation of FISH signalling. MB performed histo-pathological examination and verified the diagnosis. WER, FB and ES treated patients on the study and checked the manuscript. ES participated in the design of the study. All authors read and approved the final manuscript.

\section{Acknowledgements}

Support for the publication fee was granted by the German Research Foundation, DFG.

\section{Funding}

This research received no specific grant from any funding agency in the public, commercial, or not-for-profit sectors.

\section{Author details}

'Department of Thoracic Surgery, University Medical Center Witten/Herdecke, Lung Clinic Merheim, Campus Cologne, Ostmerheimerstrasse 200, 51109 Köln, Germany. ${ }^{2}$ Institut für Pathologie, Kliniken der Stadt Köln gGmbH, Köln, University Medical Center Witten/Herdecke Merheim, Campus Cologne, Köln, Germany.

Received: 30 December 2013 Accepted: 14 August 2014

Published: 19 August 2014

\section{References}

1. Ploenes T, Osei-Agyemang T, Nestle U, Waller CF, Passlick B: [Malignant pleural mesothelioma]. Dtsch Med Wochenschr 2012, 137(10):481-486.

2. Ploenes T, Osei-Agyemang T, Krohn A, Waller CF, Duncker-Rohr V, Elze M, Passlick B: Changes in lung function after surgery for mesothelioma. Asian Cardiovasc Thorac Ann 2013, 21(1):48-55.

3. Mir Alireza Hoda KS, Pirker C, Ghanim B, Klikovits T, Laszlo V, Setinek U, Filipits M, Dome B, Hegedues B, Marian B, Grasl-Kraupp B, Klepetko W, Berger W, Grusch M: Targeting the fibroblast growth factor receptor axis in malignant pleural mesothelioma. Cancer Res 2012, Volume 72(Issue 8). Supplement 1, Abstract nr 1067.

4. Weiss J, Sos ML, Seidel D, Peifer M, Zander T, Heuckmann JM, Ullrich RT, Menon R, Maier S, Soltermann A, Moch H, Wagener P, Fischer F, Heynck S, Koker M, Schöttle J, Leenders F, Gabler F, Dabow I, Querings S, Heukamp LC, Balke-Want H, Ansén S, Rauh D, Baessmann I, Altmüller J, Wainer Z, Conron M, Wright G, Russell P, et al: Frequent and focal FGFR1 amplification associates with therapeutically tractable FGFR1 dependency in squamous cell lung cancer. Sci Trans/ Med 2010, 2(62):62ra93.

5. Schildgen V, Pabst O, Tillmann RL, Lusebrink J, Schildgen O, Ludwig C, Brockmann M, Stoelben E: Low frequency of EGFR mutations in pleural mesothelioma patients, Cologne, Germany. Diagn Mol Pathol 2014 epublished ahead of print.

6. Okuda K, Sasaki H, Kawano O, Yukiue H, Yokoyama T, Yano M, Fujii Y: Epidermal growth factor receptor gene mutation, amplification and protein expression in malignant pleural mesothelioma. J Cancer Res Clin Oncol 2008, 134(10):1105-1111.

7. Rena O, Boldorini LR, Gaudino E, Casadio C: Epidermal growth factor receptor overexpression in malignant pleural mesothelioma: prognostic correlations. J Surg Oncol 2011, 104(6):701-705.

doi:10.1186/1756-0500-7-549

Cite this article as: Plönes et al: Absence of amplification of the FGFR1-gene in human malignant mesothelioma of the pleura: a pilot study. BMC Research Notes 2014 7:549.

\section{Submit your next manuscript to BioMed Central and take full advantage of:}

- Convenient online submission

- Thorough peer review

- No space constraints or color figure charges

- Immediate publication on acceptance

- Inclusion in PubMed, CAS, Scopus and Google Scholar

- Research which is freely available for redistribution

Submit your manuscript at www.biomedcentral.com/submit 